\title{
Analysis of the Health Spending and GDP in the Visegrad Group and in Germany
}

\author{
Martina HEDVICAKOVA ${ }^{1, *}$, Alena POZDILKOVA ${ }^{2}$ and Arkadiusz PIWOWAR ${ }^{3}$ \\ 1 University of Hradec Kralove, Hradec Kralove, Czech Republic; martina.hedvicakova@uhk.cz \\ 2 University of Pardubice, Pardubice, Czech Republic; alena.pozdilkova@upce.cz \\ 3 Wroclaw University of Economics and Business, Wroclaw, Poland; arkadiusz.piwowar@ue.wroc.pl \\ * Correspondence: martina.hedvicakova@uhk.cz
}

\begin{abstract}
The aim of this article is to analyze health care expenditures in Czech Republic and in states of Visegrad Group and Germany as a comparison. Correlation analysis with significance testing and time series prognosis will be used. Data for analysis were obtained from Eurostat and OECD. Correlation coefficients for health care expenditures and GDP per capita were calculated for individual states of the Visegrad Group and for comparison of Germany. Most correlated are these variables in Poland, where computed value is 0.9905 , which is very closed to one. It means, that trend of heath care expenditures and GDP per capita is almost the same. Subsequently, prognosis of heath care expenditures was carried out in the Czech Republic, which showed a further increase in health care expenditures by 2028, which corresponds to the demographic and economic trend. There is a similar trend in other analysis countries.
\end{abstract}

Keywords: health care expenditures; costs; correlation analysis; GDP; prognosis

JEL Classification: I15, H51, E60, C35

\section{Introduction}

Health care expenditure is a widely discussed issue in most countries in the European Union. Health protection is one of the most important topics of social policy of each EU countries (Giammanco and Gitto 2019). In recent years there has been a steady increase in healthcare expenditure. There is also an increase in life expectancy, which has a significant impact on health spending (KrabbeAlkemade et al. 2020; Frączkiewicz-Wronka et al. 2019). The health harm from pollution (air, water, etc.) leads to increased healthcare expenditures (Apergis et al. 2020; Giannakis et al. 2019; Cincinelli and Martellini 2017; Szemik et al. 2019). Polluted air is the cause of health and economic losses (Dzikuć et al. 2019; Piwowar and Dzikuć 2020).

Health systems are organized and funded in different ways in EU Member States. Finding the best universal access to quality health care at an affordable price, both for individuals and for society in general (Azzopardi-Muscat 2015; Kosycarz et al. 2019; Rechel 2019). It is generally regarded as a basic need; moreover, this is one of the common values and principles of EU health systems (Eurostat 2019).

Healthcare expenditure relative to GDP was $9.9 \%$ in the European Union in 2016. France and Germany had the highest healthcare expenditure relative to GDP in 2016. Romania and Luxembourg had the lowest healthcare expenditure relative to GDP in 2016 (Eurostat 2019).

In the reference scenario, global health spending was projected to increase from US\$10 trillion (95\% uncertainty interval 10 trillion to 10 trillion) in 2015 to $\$ 20$ trillion (18 trillion to 22 trillion) in 2040. Per capita health spending was projected to increase fastest in upper-middle-income countries, at $42 \%$ (34-51) per year, followed by lower-middle-income countries $(40 \%, 36-45)$ and low-income countries $(22 \%, 17-28)$. Despite global growth, per capita health spending was projected to range from only $\$ 40$ (24-65) to \$413 (263-668) in 2040 in low-income countries, and from $\$ 140$ (90-200) to \$1699 (711-3423) in lower-middle-income countries. (Global Burden of Disease Health Financing Collaborator Network 2018). 
Neofytidou and Fountas (2020) find that total life expectancy, male life expectancy, and female life expectancy have all a positive and statistically significant short-run and the long-run effect on both total and per capita income. As a consequence, they conclude that health should be considered an important ingredient of the economic performance of an economy.

Results of Hitiris and Posnett (1992) confirm the importance of GDP as a determinant of health spending, with an estimated income elasticity at or around unity, but also suggest that OECD countries should not be regarded as a single, homogeneous group. Hartwig (2008) tests yield robust evidence in favor of Baumol's theory that health care expenditure is driven by wage increases in excess of productivity growth. Causality between healthcare expenditure and GDP is mostly bilateral (Amiria and Venteloub 2012). Devlin and Hansen (2010) tested that for some of the 20 OECD countries tested it appears that health care expenditure Granger causes GDP, and vice versa for others. Utilizing Granger Causality within the framework of a panel cointegration model, Mehrara and Musai (2011) findings suggest that there is strong causality running from GDP and oil revenues to health expenditure with no feedback effects from health to GDP for oil exporting countries. Hedvičáková and Pozdílková (2019) shown dependence of health expenditure of households on their income. Hedvičáková and Pozdílková (2018) verified by correlation analysis the dependency health expenditure of individual households and GDP in Czech Republic between 2010 and 2017.

\section{Methodology}

Health spending measures (according to OECD 2020a) the final consumption of health care goods and services (i.e. current health expenditure) including personal health care (curative care, rehabilitative care, long-term care, ancillary services and medical goods) and collective services (prevention and public health services as well as health administration), but excluding spending on investments. Health care is financed through a mix of financing arrangements including government spending and compulsory health insurance ("Government/compulsory") as well as voluntary health insurance and private funds such as households' out-of-pocket payments, NGOs and private corporations ("Voluntary"). This indicator is presented as a total and by type of financing ("Government/compulsory", "Voluntary", "Out-of-pocket") and is measured as a share of GDP, as a share of total health spending and in USD per capita (using economy-wide PPPs).

Gross domestic product (GDP) is the standard measure of the value added created through the production of goods and services in a country during a certain period. Real gross domestic product (GDP) is GDP given in constant prices and refers to the volume level of GDP (OECDb).

The aim of correlation analysis is to determine the strength of linear dependence between quantities. Then a zero correlation coefficient means that the quantities are independent. If the assumption of two-dimensional normality is not satisfied, the zero value of the correlation coefficient cannot be inferred more than that the quantities are uncorrelated. The closer the relationship between the two variables, the closer the absolute value of the correlation coefficient is to one. Negative correlation coefficients express indirect correlation (with increasing values of one variable the values of the other variable decrease).

Significance of correlation coefficient can be verified using significance test of the correlation

coefficient. The test statistic is $T=r \sqrt{\frac{n-2}{1-r^{2}}}$, if $|T| \geq t_{n-2,0.975}$, time series are similar in character over a given time period.

Data for statistical analysis were from OECD. Used algorithms were implemented in software MATLAB, version R2013b.

\section{Results}

\subsection{Correlation analysis}

In this article correlation coefficients will be calculated, and their significance will be verified using significance test of the correlation coefficient, where the test statistic $T=r \sqrt{\frac{n-2}{1-r^{2}}}$. 
If $|T| \geq t_{13-2,0.975}=t_{11,0.975}=2.20$, series have a similar trend.

From the given relation we calculate correlation coefficient $\mathrm{r}: 2.20 \leq r \sqrt{\frac{13-2}{1-r^{2}}}$

$$
(2.2)^{2} \leq \frac{r^{2}}{\sqrt{1-r^{2}}} \sqrt{11} \Rightarrow \frac{r^{2}}{\sqrt{1-r^{2}}} \geq \frac{(2.2)^{2}}{\sqrt{11}}=1.4593 \Rightarrow|r| \geq 0.8612
$$

We will compute correlation coefficients for health care expenditures and GDP per capita in years 2005-2018 in countries of Visegrad Group. Correlation coefficients for these countries are following:

- $\quad$ Czech Republic 0.9646;

- Slovak Republic 0.9390;

- Hungary 0.9252;

- $\quad$ Poland 0.9905.

All these values are greater than calculated $r$, so all countries of Visegrad Group have the same trend of growth of health care expenditures and GDP. Most correlated are these variables in Poland, where computed value is 0.9905 , which is very closed to one.

Following Figure 1 and 2 show similar trends of health care expenditures and GDP per capita in V4 countries.

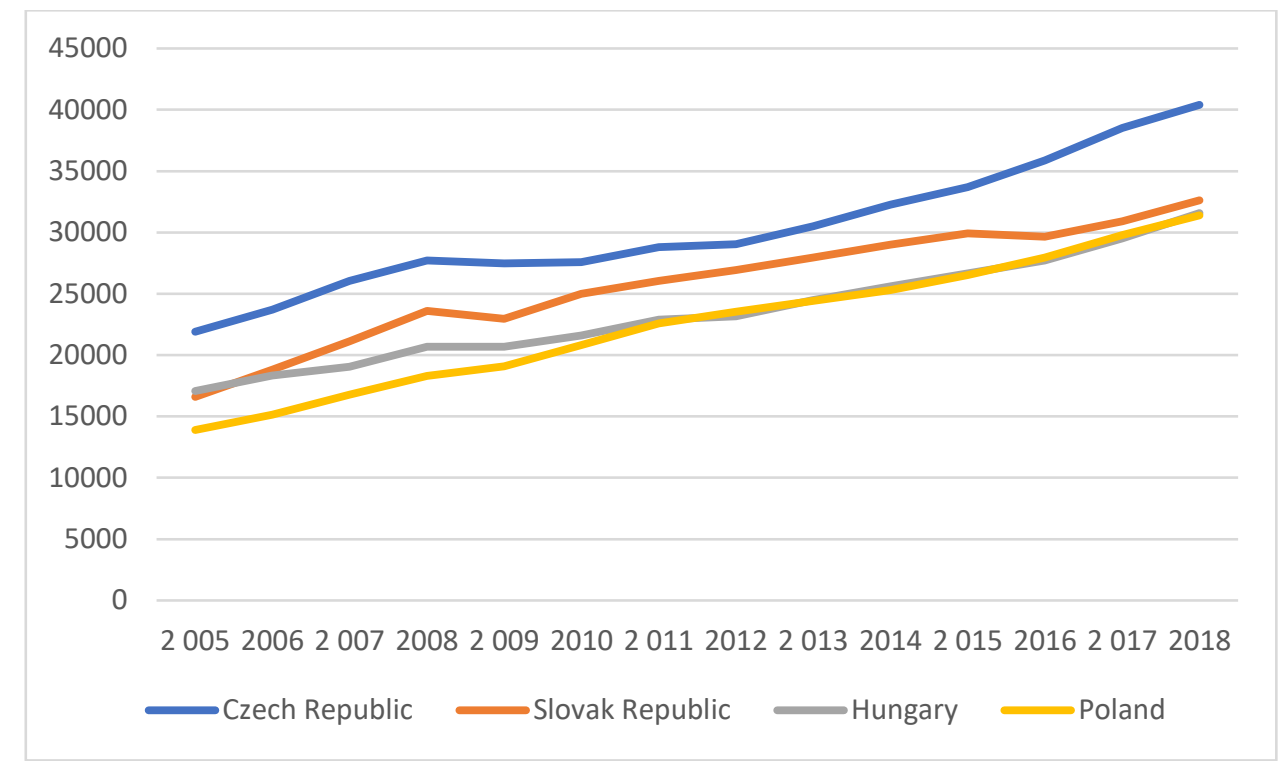

Figure 1. GDP in US dollars/capita for Visegrad group in 2005-2018.

Health care expenditures are growing fastest in the Czech Republic. The lowest cost of health expenditure is in Poland in the years 2005-2016. Since 2017, however, the growth of health expenditure in Poland has stagnated. However, the expenditure for health in Poland is in fact too little. Health care costs are the lowest in Hungary since 2017 (see Figure 2).

The trend in GDP expenditure (see Fig. 1) in the Czech Republic can be observed. In 2008, economic growth came to a halt and the financial and subsequently economic crisis started. The following year, GDP values declined. Since 2013, there has been economic growth and economic recovery in the Czech Republic, which resulted in a rise in GDP values and a decline in the unemployment rate. 


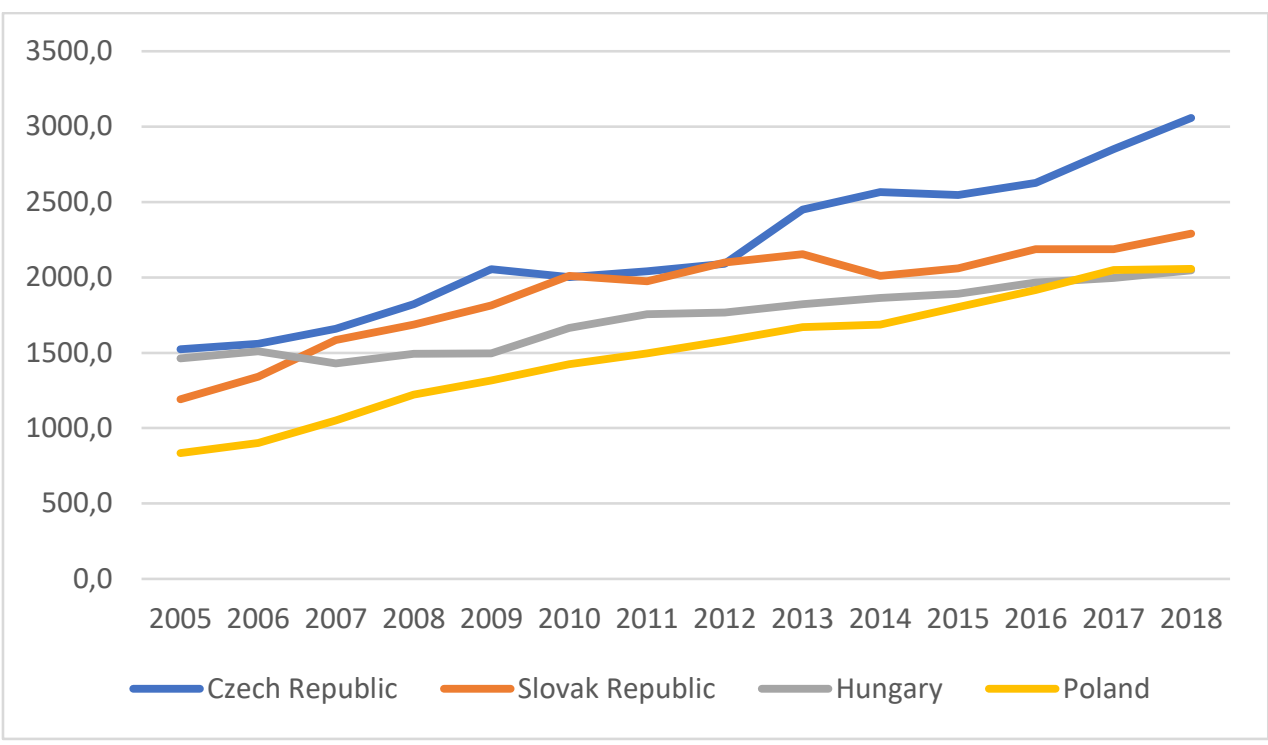

Figure 2. Health spending of the Visegrad Four in US dollars/capita in 2005 - 2018.

In opposite of these results is correlation coefficient between Health care expenditures and GDP of Germany, which is 0.3388 , so these variables are not correlated and trends of development of GDP and Health care expenditures are not significantly similar. It can be seen on following Figure 3.

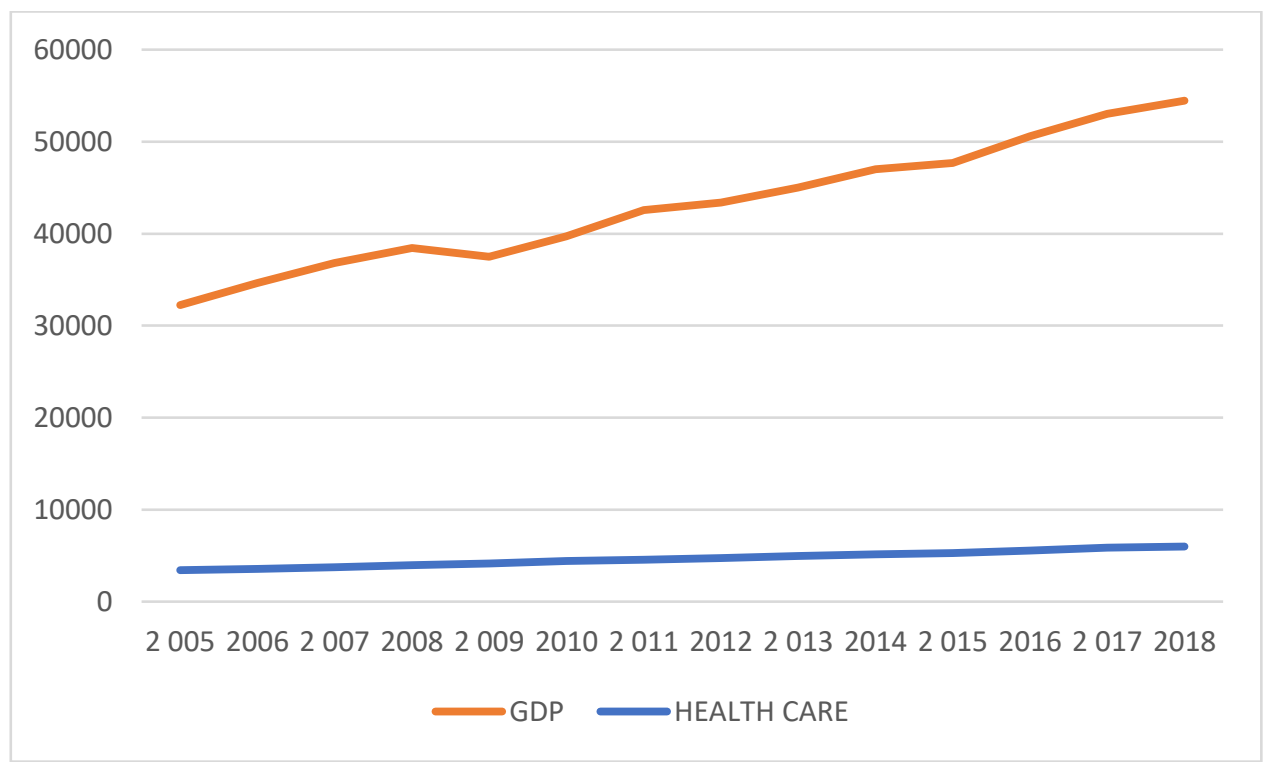

Figure 3. GDP (US dollars/capita) in the Germany in 20052018.

Health care costs are rising continuously in Germany (see Figure 3). Germany has the second highest expenditure on health care in relation to GDP in the European Union. The share of health expenditure in relation to GDP was $11.1 \%$ in 2016. Germany has the highest expenditure on health in the whole European Union. Expenditure on health in 2006 totaled EUR 242,121 million and in 2016 totaled EUR 351,701 million. The change between 2006 and 2016 is EUR 109,580 million in Germany. The second largest expenditure on health was France $€ 257,194$ million in 2016 . The change between 2006 and 2016 was only $€ 65,781$ million in France. However, the share of health expenditure in GDP in 2006 and 2016 was the highest in France: 11.5\%.

GDP development in Germany (see Figure 3) is also the same as in the Czech Republic. GDP growth stopped in 2008 and the economic crisis followed, but it was shorter than in the Czech Republic. In Germany, there was a faster recovery and economic growth. 
Correlation coefficients were calculated for individual states of the Visegrad Group and for comparison of Germany. Germany was chosen because it has the highest healthcare expenditure from the European Union and is the dominant trading partner for the Czech Republic. On the foreign trade turnover of the Czech Republic, Germany participates in more than $29 \%$.

\subsection{Prognosis of heath care expenditures in the Czech Republic}

Prognosis of heath care expenditures in the Czech Republic is following (similar growing trend will have all states of Visegrad Group).

Table 1. Prognosis of health care expenditures (in US dollars/capita) in the Czech Republic.

\begin{tabular}{cccc}
\hline Year & Prognosis & Confidence - lower bound & Confidence - upper bound \\
\hline 2010 & 2001,1 & & \\
2011 & 2041,9 & & \\
2012 & 2090,5 & & \\
2013 & 2448,5 & & \\
2014 & 2564,6 & & \\
2015 & 2545,5 & & 3057,6 \\
2016 & 2627,7 & & 3204,0 \\
2017 & 2850,4 & & 3176,9 \\
2018 & 3057,6 & 3057,6 & 3283,2 \\
2019 & & 3315,6 & 3373,2 \\
2020 & & 3301,7 & 3637,1 \\
2021 & & 3433,5 & 3839,2 \\
2022 & & 3560,5 & 3765,2 \\
2023 & & 3870,7 & 3831,4 \\
2024 & & 4126,7 & 3888,0 \\
2025 & & 4112,8 & 4123,5 \\
2026 & & 4244,6 & \\
2027 & & 4371,6 & \\
2028 & & 4681,8 & \\
\hline
\end{tabular}

According to the forecast (see Table 1 and Figure 4), the growing trend in health expenditure will continue until 2028. This forecast reflects the economic situation as the population in the Czech Republic is aging. Average life expectancy increases.

Next graph shows prognosis of health care expenditures for years 2019-2022. Graph includes also lower bounds and upper bounds for this prognosis. 


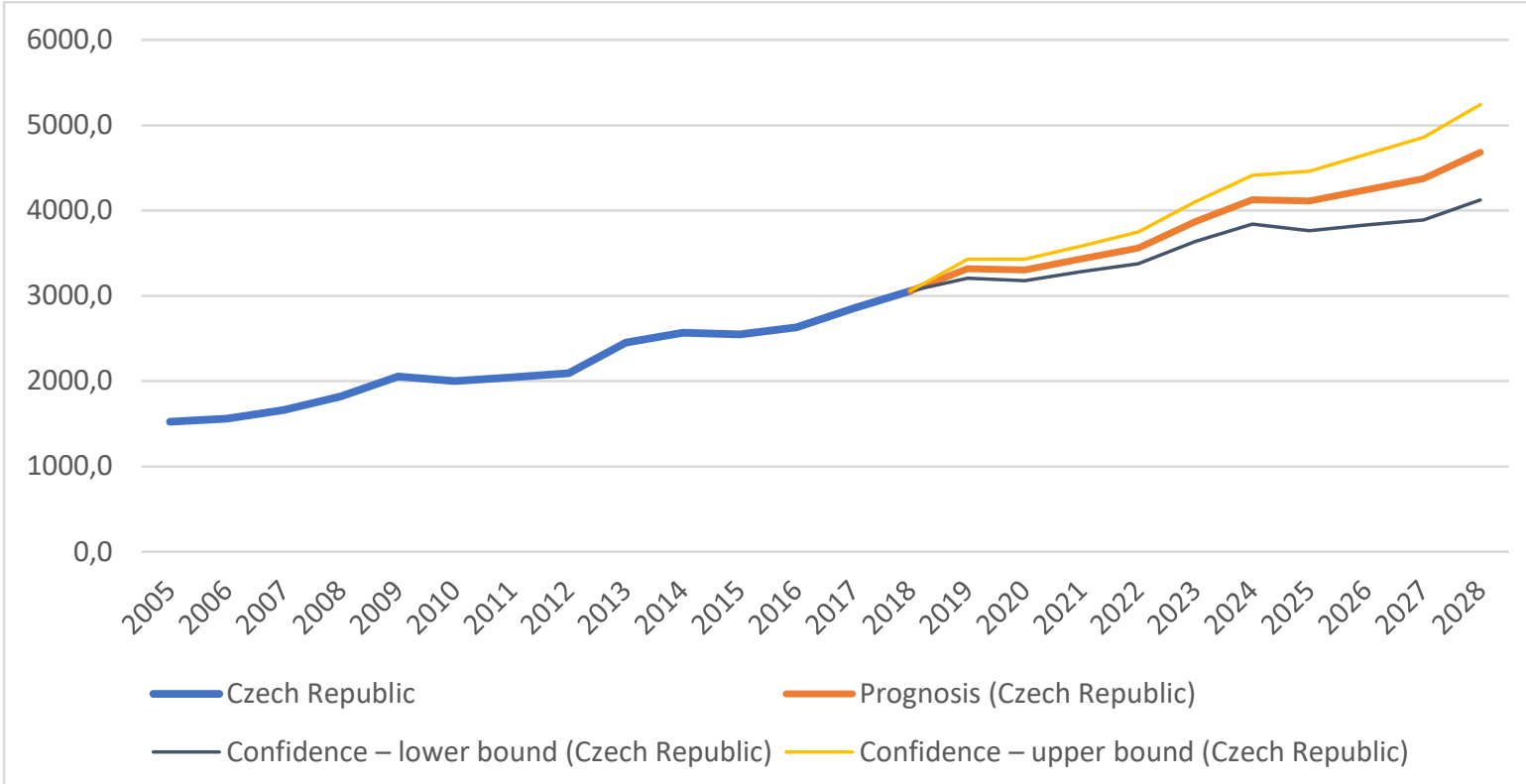

Figure 4. Prognosis of health care expenditures (in US dollars/capita) in the Czech Republic.

For comparison is the same graph prognosis of health care expenditures for years 2019-2022 computed also for Germany. Figure 5 includes also lower bounds and upper bounds for this prognosis.

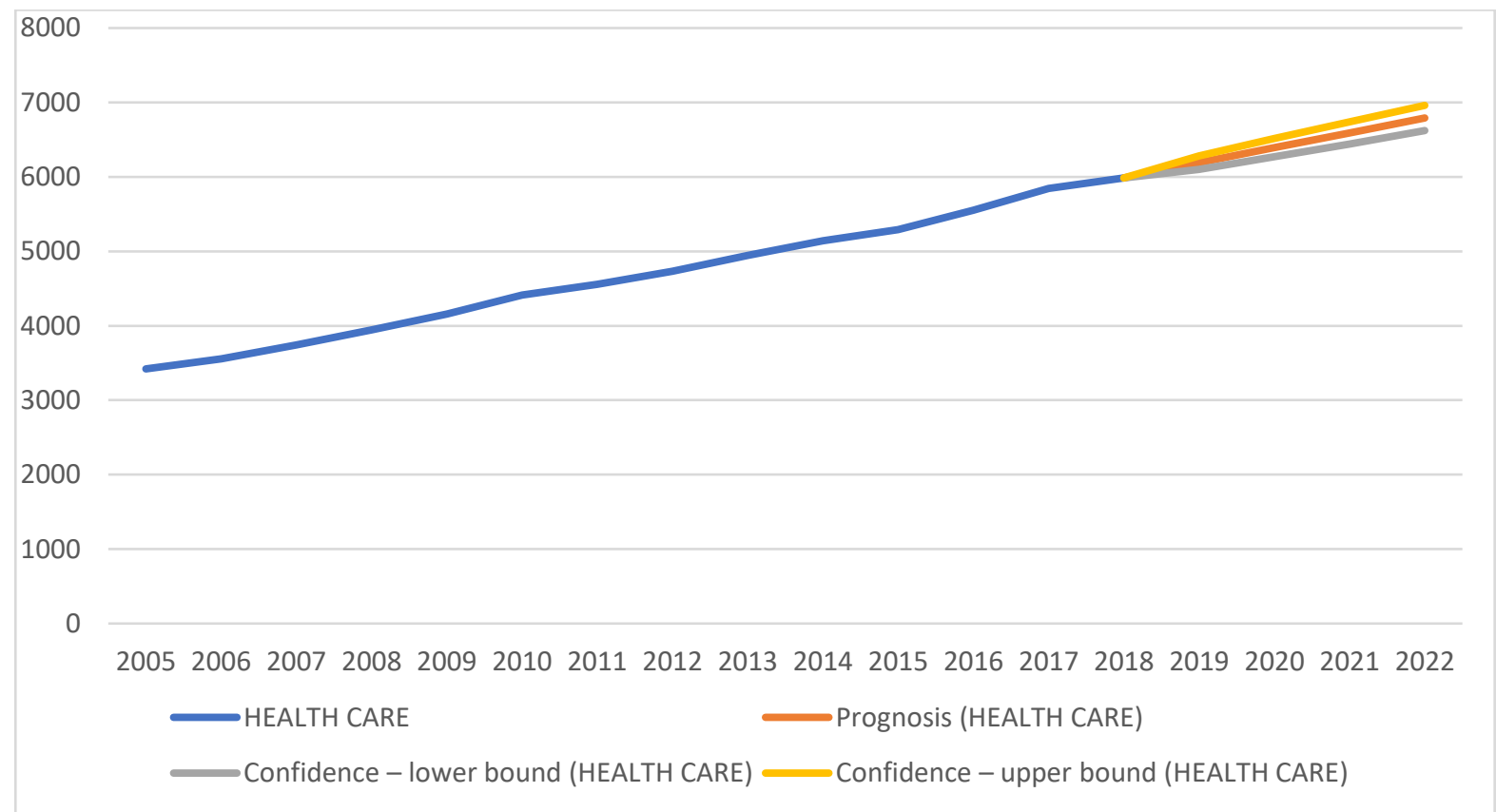

Figure 5. Prognosis of health care expenditures (in US dollars/capita) in Germany.

Regarding to the development of health expenditure in Germany in the years 2005-2018, the prognosis of further development of health expenditure is increasing. This forecast corresponds to GDP development and the current economic situation.

\section{Discussion}

According to the forecast of the development of health care expenditures, further growth will occur in the following years. The question to be discussed is how this growth in health care expenditure will also be affected by the aging of the population that occurs in the countries surveyed. 
An aging population is also pointed out by (Simmons 1986), which states that the increase in the elderly population has increased the demand for geriatric medicine.

Lambo (1993) attempts to bring into focus the linkages between the economy and the health sector and the proffer to policy makers and planners, what should be done in the future to minimize the negative impact of macro and sectoral policies on health.

Another important aspect influencing the development of health care expenditures will be medical technology and healthcare innovation. The advent of the fourth industrial revolution Industry 4.0 will also be reflected in medicine. Hedvicakova and Kral (2019) examined the impact of the Industry 4.0 initiative on individual sectors and the unemployment rate. Raftery and Powell (2013) identify features that might be of value to other health systems as they confront the challenges of rapid innovation and rising costs. Hedvicakova and Svobodova (2015) deals with the economic situation in the Visegrad countries. The Czech Republic has good economic conditions for further GDP growth, but it is a small open economy. Its economic situation is influenced by the economic situation in Germany.

Another issue to discuss is the correct measurement of healthcare costs. For example, Král and Hájek (2018) analyzed the cost expression.

\section{Conclusions}

The Czech Republic has the highest expenditure on health care from the Visegrad Group. It also has the highest GDP growth. Slovakia is second in terms of both health expenditure and GDP growth. Poland and Hungary have had similar health care expenditures over the past two years. They also achieve similar results in terms of GDP. Hungary is ranked 18th in the ratio of health care expenditure relative to GDP ratio from the EU countries in 2016. The Czech Republic ranked two positions less, with a ratio of health care expenditure relative to GDP of 7.1\%. Slovakia has the same ratio. Poland has healthcare spending relative to GDP of 6.5\% in 2016. Latvia, Luxemburg and Romania are only behind Poland. Romania has the lowest proportion of healthcare expenditure across the European Union: only $5 \%$.

According to the forecast, health care expenditure is expected to grow in the coming years. Demographic developments confirm this forecast. Overall, the population of the Czech Republic has been growing over the long term. The population is aging. The highest increases in the population are concentrated in the age group 65+. In 2018, over 58,000 people moved to the Czech Republic, most in the last ten years. The balance of foreign migration is usually positive in the Czech Republic. A similar trend in the growth of health care expenditures is in other Visegrad countries.

The correlation coefficients for health care expenditures and GDP per capita was calculated for states of the Visegrad Group and Germany in years 2005-2018. All of these values are larger than computed coefficient for testing significance of correlation, so the trend of growth in health care expenditure and GDP is similar. Most correlated are these variables in Poland, where the computed value is 0.9905 , which is very closed to one. Thus, the trend of heath care expenditures and GDP per capita in Poland is almost the same. For comparison was the correlation coefficient computed also in Germany, where is smaller than coefficient for testing significance of correlation. It means, that trends of heath care expenditures and GDP per capita in Germany are not similar.

All computed results are illustrated by graphs, that confirm the results.

Acknowledgments: The paper is supported by the project of Technological Agency of the Czech Republic, TL01000300 Treatment and care of people with Alzheimer's disease - economic burden in the context of the development of new drugs.

\section{References}

Apergis Nicholas, Bhattacharya Mita, and Walid Hadhri. 2020. Health care expenditure and environmental pollution: a cross-country comparison across different income groups. Environmental Science and Pollution Research: 1-15. https://doi.org/10.1007/s11356-019-07457-0. 
Amiria Arshia, and Ventelou Bruno. 2012. Granger causality between total expenditure on health and GDP in OECD: Evidence from the Toda-Yamamoto approach. Economics Letters: 116(3), 541-544. https://doi.org/10.1016/j.econlet.2012.04.040.

Azzopardi-Muscat Natasha, Clemens Timo, Stoner Deborah, and Brand Helmut. 2015. EU Country Specific Recommendations for health systems in the European Semester process: Trends, discourse and predictors. Health Policy: 119(3), 375-383. https://doi.org/10.1016/j.healthpol.2015.01.007.

Cincinelli Alessandra, and Martellini Tania. 2017. Indoor Air Quality and Health, International. Journal of Environmental Research and Public Health: 14(11), 1286. https://doi.org/10.3390/ijerph14111286.

Devlin Nancy, and Hansen Paul. 2001. Health care spending and economic output: Granger causality. Applied Economics Letters: 8, 561-564. https://doi.org/10.1080/13504850010017357.

Dzikuć Maciej, Kułyk Piotr, Urban Stanislaw, Dzikuć Maria, and Piwowar Arkadiusz. 2019. Outline of ecological and economic problems associated with the low emission reductions in the Lubuskie Voivodeship. Polish Journal of Environmental Studies: 28(1), 65-72. https://doi.org/10.15244/pjoes/83612.

Eurostat. 2019. Healthcare expenditure statistics. Available online: https://ec.europa.eu/eurostat/statisticsexplained/index.php?title=Healthcare_expenditure_statistics. (accessed on 18 December 2019).

Frączkiewicz-Wronka Aldona, Kowalska-Bobko Iwona, Sagan Anna, and Wronka-Pośpiech Martyna. 2019. The growing role of senior's councils in health policy-making for older people in Poland. Health Policy: 123(10), 906-911. https://doi.org/10.1016/j.healthpol.2019.05.016.

Giammanco Maria Damiela, and Gitto Lara. 2019. Health expenditure and FDI in Europe. Economic Analysis and Policy: 62, 255-267. https://doi.org/10.1016/j.eap.2019.04.001.

Giannakis Elias, Kushta Jonilda, Giannadaki Despina, Georgiou George K., Bruggeman Adriana, and Lelieveld Jos. 2019. Exploring the economy-wide effects of agriculture on air quality and health: evidence from Europe. Science of The Total Environment: 663, 889-900. https://doi.org/10.1016/j.scitotenv.2019.01.410.

Global Burden of Disease Health Financing Collaborator Network. 2018. Trends in future health financing and coverage: future health spending and universal health coverage in 188 countries, 2016-40. The Lancet: 391, (10132), 1783-1798. https://doi.org/10.1016/S0140-6736(18)30697-4.

Hartwig Jochen. 2008. What drives health care expenditure? - Baumol's model of 'unbalanced growth' revisited. Journal of Health Economics: 27(3), 603-623. https://doi.org/10.1016/j.jhealeco.2007.05.006.

Hedvičáková Martina, and Král Martin. 2019. Benefits of KPIs for industry sector evaluation: The case study from the Czech Republic. EEM Ekonomie a Management: 22(2), 97-113. https://doi.org/10.15240/tul/001/2019-2-007.

Hedvičáková Martina, and Pozdílková Alena. 2019. Analysis of Health Care Expenditures in the Czech Republic and European Union. Liberec economic forum 2019: proceedings of the 14th international conference, Liberec, Czech Republic, 17th-18th September 2019, pp. 189-197. Available online: http://lef.tul.cz/assets/lef_2019_proceedings_.pdf (accessed on 18 December 2019).

Hedvičáková Martina, and Pozdílková Alena. (2018). Analytical and statistical research of state and households health care expenditures in the Czech Republic. Hradec Economic Days, Vol. 8(1), Double-blind peerreviewed proceedings part I. of the International Scientific Conference Hradec Economic Days 2018, January 30-31, 2018, Hradec Králové, Czech Republic, pp. 311-318. Available online: https://uni.uhk.cz/hed/site/assets/files/1072/proceedings_2018_1.pdf (accessed on 9 December 2019).

Hitiris Theo, and Posnett John. 1992. The determinants and effects of health expenditure in developed countries. Journal of Health Economics: 11(2), 173-181. https://doi.org/10.1016/0167-6296(92)90033-W.

Kosycarz Ewa Agnieszka, Nowakowska Beata Anna, and Mikołajczyk Marcin Mateus. 2019. Evaluating opportunities for successful public-private partnership in the healthcare sector in Poland. Journal of Public Health: 27(1), 1-9. https://doi.org/10.1007/s10389-018-0920-x.

Krabbe-Alkemade Yvonne, Makai Peter, Shestalova Victoria, and Voesenek Tessa. 2020. Containing or shifting? Health expenditure decomposition for the aging Dutch population after a major reform. Health Policy. https://doi.org/10.1016/j.healthpol.2019.12.016 (in press).

Král Martin, and Hájek Ladislav. (2018). Analysis of Parliamentary Elections Costs in the Czech Republic. In Double-blind peer-reviewed proceedings part I. of the International Scientific Conference Hradec Economic Days 2018. Hradec Králové: Univerzita Hradec Králové, pp. 472-481. Available online: https://uni.uhk.cz/hed/site/assets/files/1072/proceedings_2018_1.pdf.

Lambo Eyitayo. 1993. The economy and health. Health Policy: 23(3), 247-263. https://doi.org/10.1016/01688510(93)90061-S.

Mehrara Mohsem, and Musai Maysam. 2011. Granger causality between Health and Economic Growth in oil exporting countries. Interdisciplinary Journal of Research in Business: 1(8), 103-108. 
Neofytidou Aliona, and Fountas Stilianos. 2020. The impact of health on GDP: A panel data investigation. The Journal of Economic Asymmetries: 21, e00139. https://doi.org/10.1016/j.jeca.2019.e00139.

OECD. 2020a. Health spending (indicator). Available online: https://doi.org/10.1787/8643de7e-en (Accessed on 28 January 2020).

OECD. 2020b. Gross domestic product (GDP) (indicator). https://doi.org/10.1787/dc2f7aec-en (Accessed on 28 January 2020).

Piwowar Arkadiusz, and Dzikuć Maciej. (2019). Development of Renewable Energy Sources in the Context of Threats Resulting from Low-Altitude Emissions in Rural Areas in Poland: A Review. Energies 2019: 12, 3558. https://doi.org/10.3390/en12183558.

Raftery James, and Powell John. 2013. Health Technology Assessment in the UK. The Lancet: 382(9900), 1278-1285. https://doi.org/10.1016/S0140-6736(13)61724-9.

Rechel Bernd. 2019. Funding for public health in Europe in decline? Health Policy: 123(1), 21-26. https://doi.org/10.1016/j.healthpol.2018.11.014.

Simmons W. June. 1986. Planning for Discharge with the Elderly. QRB - Quality Review Bulletin: 12(2), 68-71. https://doi.org/10.1016/S0097-5990(16)30011-2.

Svobodová Libuse, and Hedvicakova Martina. 2015. Doing Business in the Countries of Visegrad Group. Procedia Economics and Finance: 34, 453-460. https://doi.org/10.1016/S2212-5671(15)01654-8.

Szemik Szymon, Kowalska Malgorzata, and Kulik Halina. 2019. Quality of life and health among people living in an industrial area of Poland. International journal of environmental research and public health: 16(7), 1221. https://doi.org/10.3390/ijerph16071221. 